\title{
Study of functional performance improvements for cutting teeth mounted on bucket wheel excavators operating in Oltenia coal basin - Romania
}

\begin{abstract}
The values of the resultant forces acting on the cutting teeth of BWEs can either be calculated or determined using experimental methods. Based on this, the position and parameters of the working organs during the cutting process are designed and built. The stresses and deformations of the teeth during the cutting process are influenced by their positioning on the excavator bucket, which is determined by the fitting mode of the teeth. In this paper, the stresses and deformations in the case of an existing tooth holder are analysed and a new type of tooth holder is proposed, using SolidWorks ${ }^{\circledR}$ software for this analysis.
\end{abstract}

Key words: deformation, stress, rotor, cutting tooth, BWE, tooth holder, FEM, FEA

\section{INTRODUCTION}

At the request of the Oltenia Energy Complex, we conducted a comparative study regarding the forces and deformations on an existing and new tooth holder that was implemented in the Oltenia open pit mines using finite element analysis. FEA is a numerical analysis method used to solve problems in various fields of engineering. In mechanical engineering, it is widely used to solve structural, vibrational, and thermal problems.

\section{INFLUENCE OF LOCATION OF CUTINGTEETH ON BUCKET ON GEOMETRIC AND STRENGTH PARAMETERS}

The positioning and orientation of the cutting teeth on the edge of the bucket influences their geometry and strength $[1,2]$. Overall, the magnitude and direction of the velocity vector are determined by the variation of swivel velocity $v_{p}$ (the range of variation being determined by the type of swivelling mechanism). Swivelling velocity $v_{p}$ is composed of cutting speed $v_{t}$, which is considered constant [3].
To study the influence of teeth placement on the geometric and strength parameters, we defined the following planes:

1. The setting plane - defined by the cutting edge of the tooth and its positioning face (Fig. 1).

2. The rake plane - defined by the cutting edge of the tooth and its rake face (Fig. 1).

3. The symmetry - perpendicular to the cutting edge and through the middle of the cutting edge (Fig. 1).

4. The cutting plane - defined by the tooth's cutting edge and the resultant vector of velocity (Fig. 2).

5. The velocity plane - perpendicular to the cutting plane; contains the resultant vector of velocity (Fig. 2).

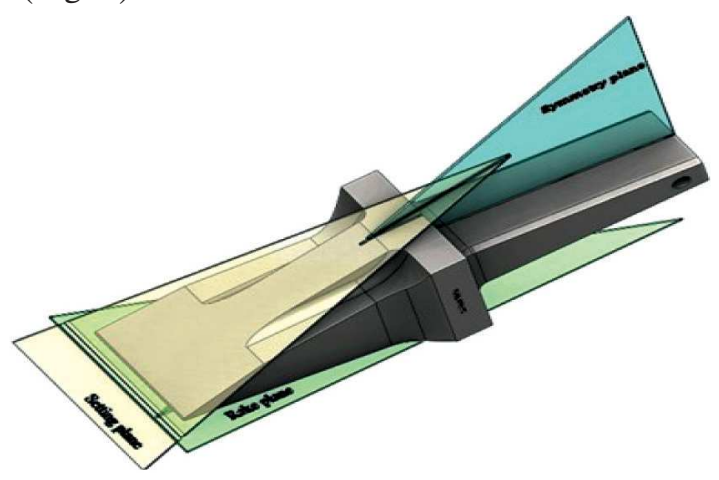

Fig. 1. Planes of setting, rake, and symmetry 


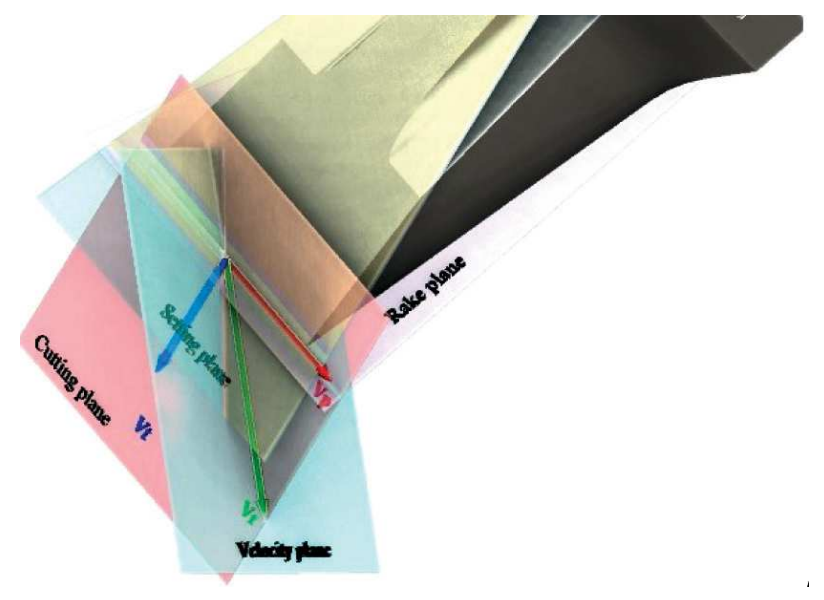

Fig. 2. Swivelling, cutting, and resultant velocities; cutting and velocity planes

If the resultant vector of velocity is perpendicular to the cutting edge of the tooth, then the velocity plane and symmetry plane overlap.

In Figure 2, the setting angle is measured between the setting plane and the cutting plane, and the angle of sharpening is measured between the cutting plane and the rake plane. Here, we noted the swivelling velocity as $v_{p}$, the cutting speed as $v_{t}$, and the resultant speed as $v_{r}$.

The angle between the line resulting from the intersection of the cutting plane with the symmetry plane and the resultant velocity vector designates the angle of the tooth positioning on the cutting edge of the bucket. Placing the tooth on the cutting edge is done through its holder [4].

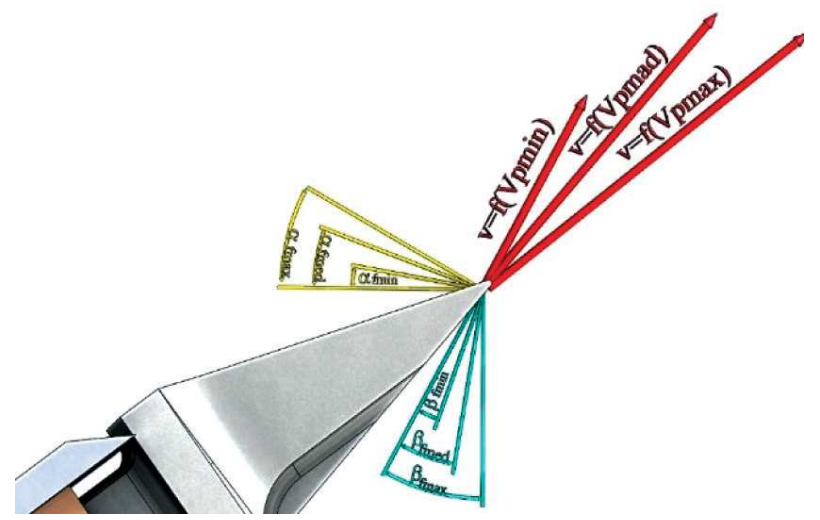

Fig. 3. Characteristic angles in operation

In operation, the characteristic angles (Fig. 3) are as follows:

- the set angle of operation $\beta_{f}$, which is the angle between the resultant velocity direction and the intersection line between the set plane and the velocity plane;
- the cutting angle in operation, which is the angle between the resultant velocity, direction, and intersection line between the rake plane and the velocity plane;

- the sharpening angle in operation, which is the angle between the intersection line of the set planes and the velocity plane, respectively, and the intersection line between the clearance plane and the velocity plane;

- the raking angle in operation $\alpha_{f}$ is complementary to set angle $\beta_{f}$.

\section{DETERMINATION OF STRESSES AND DE FORMATIONS FOR CHISEL-TYPE CUTTING TEETH USING OLD TOOTH HOLDER}

In past research from the University of Petro?ani conducted for the Oltenia Power Complex, three types of cutting teeth for BWEs were proposed. Figure 4 shows the construction of such a tooth, and Figure 5 shows the type dimensional differences between the three types of teeth $[5,6]$.

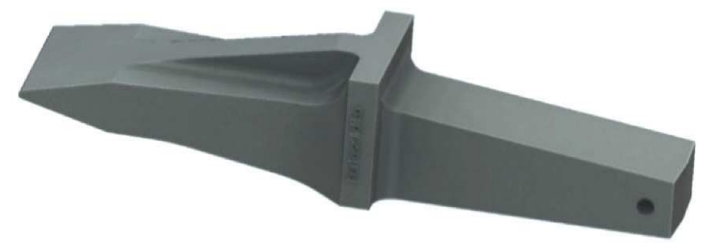

Fig. 4. Cutting tooth chosen for analysis

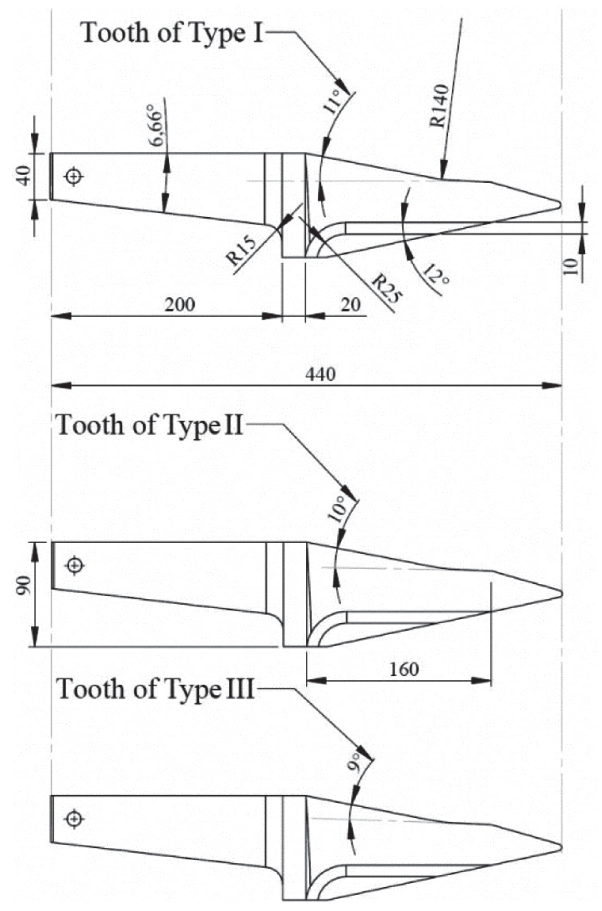

Fig. 5. Type dimensions of the proposed cutting tooth 
The dimensions correspond to the three distinct categories of the excavated material, each having its specific cutting resistance:

Overburden rocks that are easily dislocated, having a low specific cutting resistance $(A=200-450 \mathrm{~N} / \mathrm{cm})$;

Overburden rocks and lignite with a medium specific cutting resistance $(A=450-800 \mathrm{~N} / \mathrm{cm})$;

Lignite having a higher specific cutting resistance $(A=800-1200 \mathrm{~N} / \mathrm{cm})$.

The stresses on the cutting-tooth are as follows: $F_{x}=60 \mathrm{kN} ; F_{y}=18 \mathrm{kN}$; and $F_{z}=10 \mathrm{kN}$.

In relation to tooth surfaces, we will have the following component forces [7]:

$$
\begin{aligned}
& F_{y 1}=F_{x} \cos \alpha-F_{y} \cos \gamma=25.857 \cdot 10^{3} \mathrm{~N} \\
& F_{x 1}=F_{x} \sin \alpha-F_{y} \sin \gamma=36.198 \cdot 10^{3} \mathrm{~N} \\
& F_{z 1}=10 \cdot 10^{3} \mathrm{~N}
\end{aligned}
$$

Figure 6 shows the deformation, and Figure 7 shows the von Mises stress resulting from the FEA on Type I when the tooth is mounted with the old tooth holder.

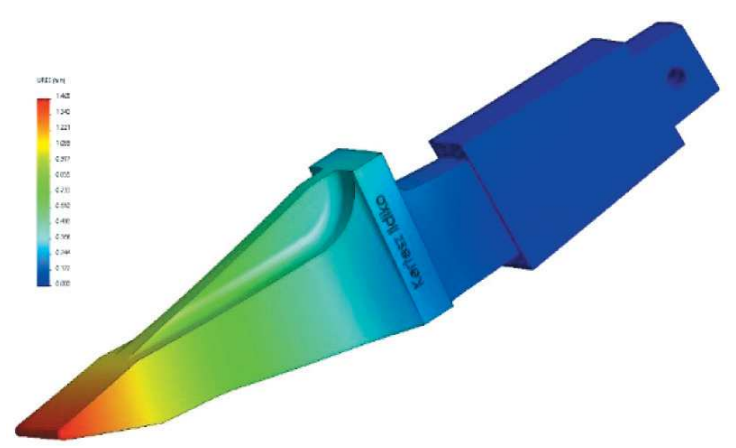

Fig. 6. Type I cutting-tooth deformation, when mounted with the old tooth holder

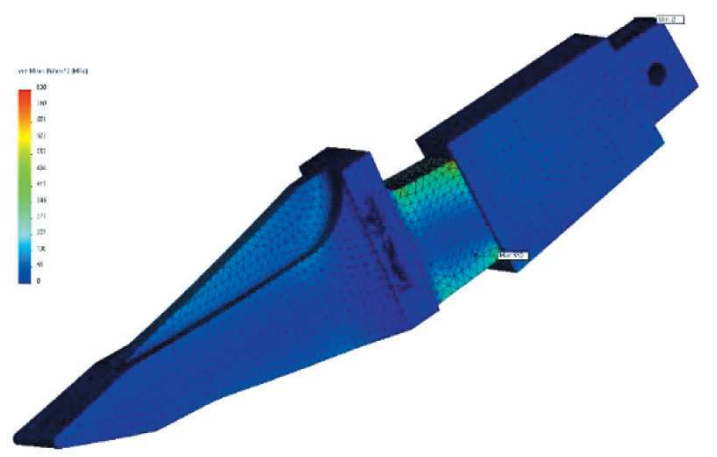

Fig. 7. Type I cutting tooth von Mises stress when mounted with old tooth holder
One can observe that the maximum deformation occurs in the area of the tip of the tooth, and the most stressed points of the tooth structure are those corresponding to its tail (between the tooth-support and the shoulder of the tooth).

\section{PROPOSED SOLUTION TO REDUCE STRESSES ACTING ON CUTTING TOOTH}

As shown in the previous paragraph, the maximum stress points are located where the section of the tooth-holder assembly presents vaulting. In the present case, it is the area of switching from the tooth-holder section to the actual tooth section. Next, we propose and analyse a type of tooth holder that will better encompass the tooth's tail. Figures 8 and 9 show the details of this new version of tooth holder.

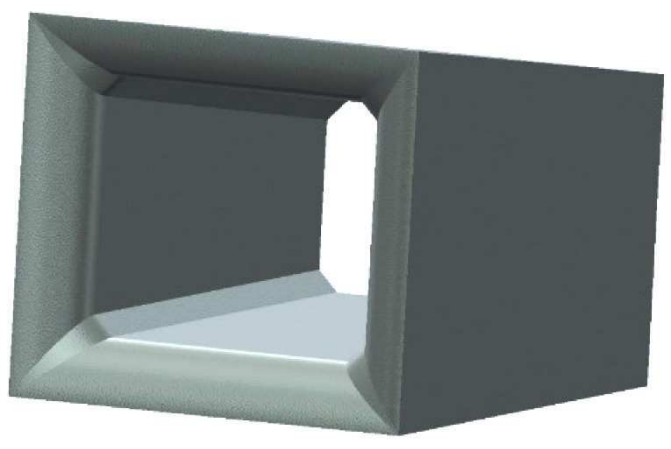

Fig. 8. Proposed holder for fitting cutting tooth to bucket
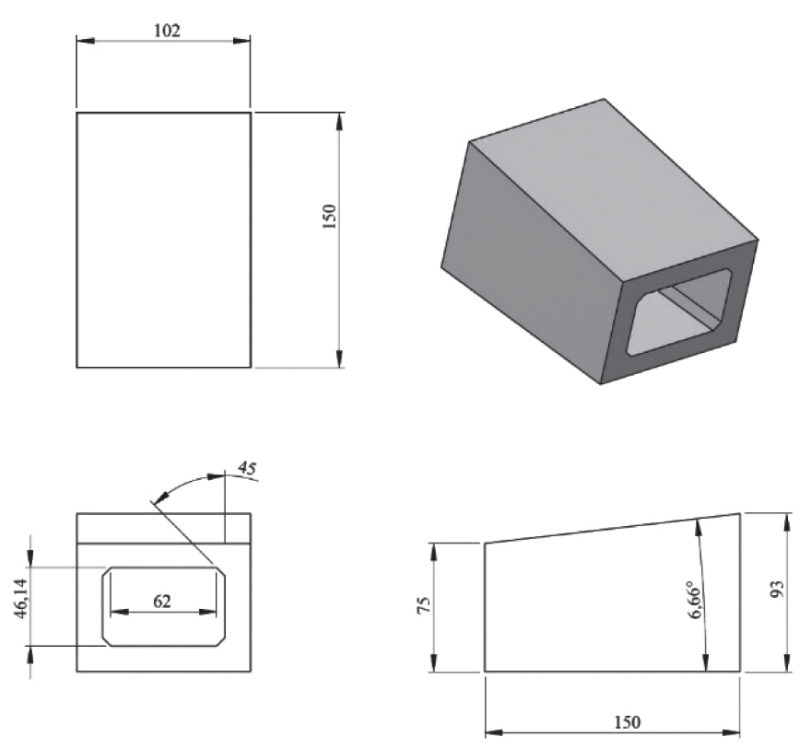

Fig. 9. Dimensions and geometry of proposed new tooth support 


\section{DETERMINATION OF STRESSES \\ AND DEFORMATION \\ FOR CHISEL-TYPE CUTTING TOOTH \\ USING NEW TOOTH HOLDER}

By imposing the stresses from Paragraph 2, we determined the deformations and stresses of the three type dimensions of the tooth proposed for analysis

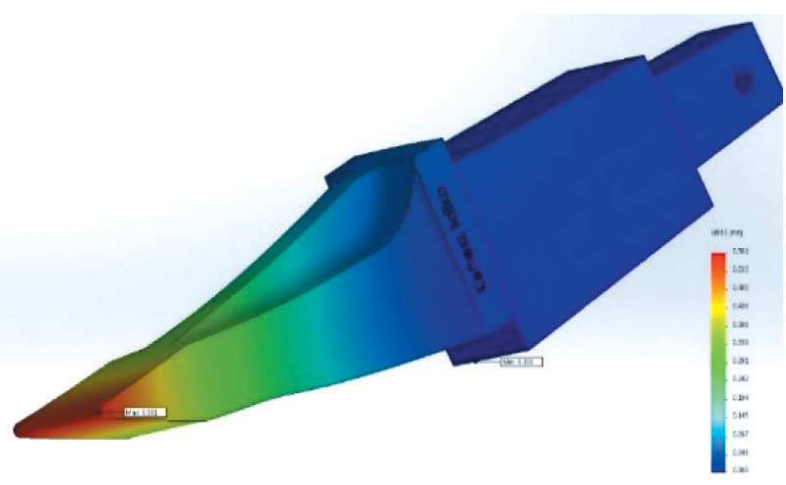

Fig. 10. Type I tooth deformation when mounted with new proposed tooth holder

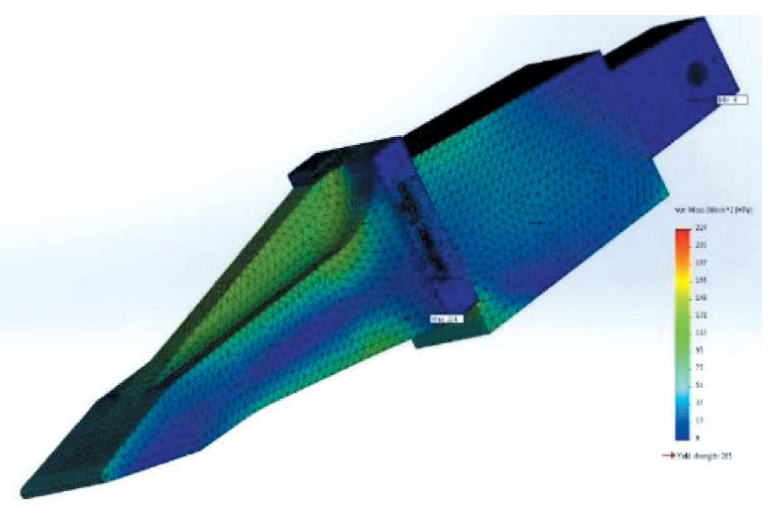

Fig. 11. Type I tooth von Misses stress when mounted with new proposed tooth holder

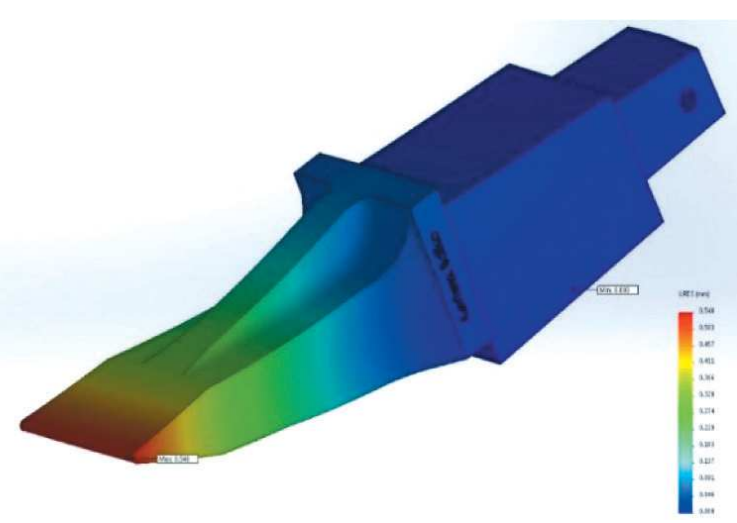

Fig. 12. Type II tooth deformation when mounted with new proposed tooth holder when it is mounted on the buckets with the new tooth holder proposed in Paragraph $3[8,9]$.

Figures 10, 12, and 14 show the deformations, and Figures 11, 13, and 15 show the von Mises stresses corresponding to the three types. The results obtained using the FEA for these tooth-type dimensions are summarized in Table 1.

The results obtained after the FEA of the three types of teeth are summarized in Table 1.

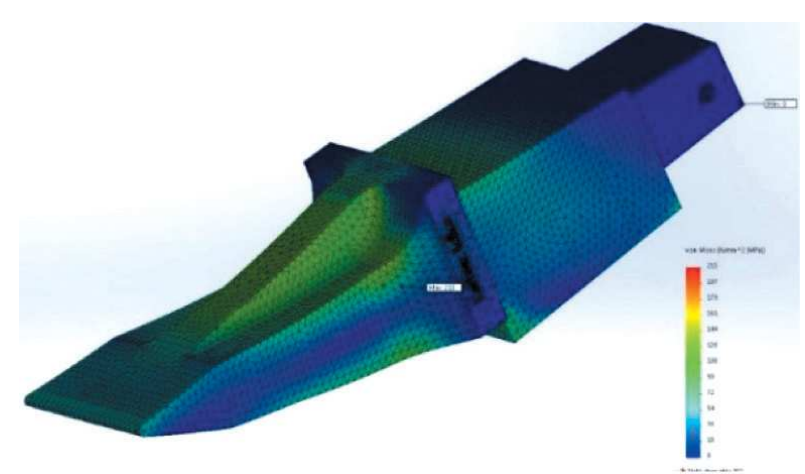

Fig. 13. Type II tooth von Misses stress when mounted with new proposed tooth holder

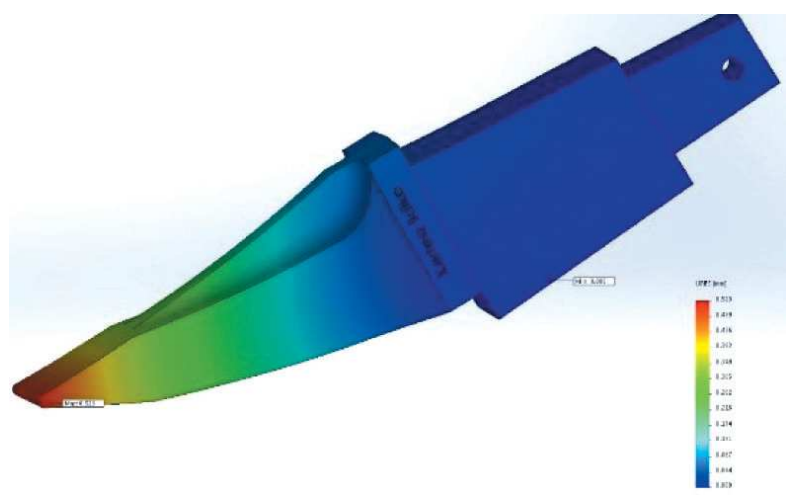

Fig. 14. Type III tooth deformation when mounted with new proposed tooth holder

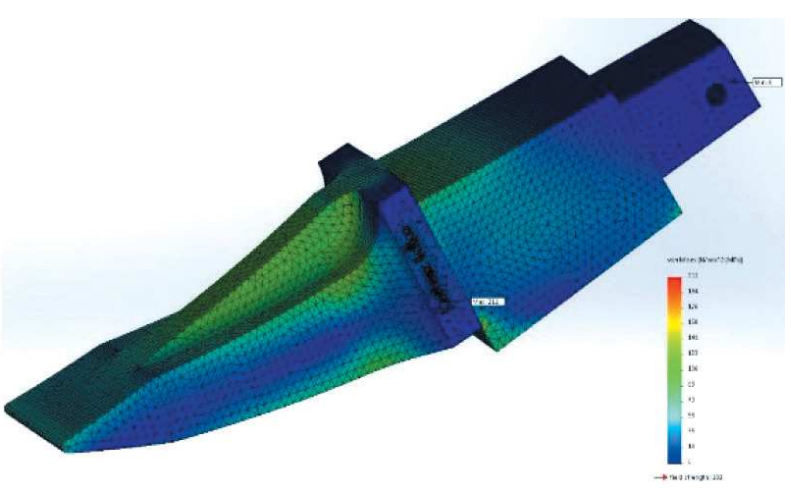

Fig. 15. Type III tooth von Misses stress when mounted with new proposed tooth 
Table 1

Summarized results obtained for three types of teeth after FEA

\begin{tabular}{|c|c|c|c|c|c|}
\hline \multirow{2}{*}{ No. } & \multirow{2}{*}{$\begin{array}{c}\text { Type } \\
\text { of tooth }\end{array}$} & \multirow{2}{*}{$\begin{array}{l}\text { Holder } \\
\text { type }\end{array}$} & Angle & Deformation & Stress \\
\hline & & & {$\left[{ }^{\circ}\right]$} & {$[\mathrm{mm}]$} & {$\left[\mathrm{N} / \mathbf{m m}^{2}\right]$} \\
\hline 1 & \multirow{2}{*}{ I } & old & \multirow{2}{*}{11} & 1.465 & 829 \\
\hline 2 & & new & & 0.581 & 224 \\
\hline 3 & II & new & 10 & 0.548 & 215 \\
\hline 4 & III & new & 9 & 0.523 & 211 \\
\hline
\end{tabular}

\section{CONCLUSIONS}

The simulation of the cutting-teeth behaviour when mounted on the BWEs using FEA was based on the results [10] obtained over the years by the Department of Mechanical, Industrial, and Transport Engineering during research contracts aimed at improving the performance of BWEs operating in the Oltenia Coal Basin.

The analysis was done on three type dimensions of teeth using FEA. An assembly of a tooth and tooth support was used in all cases. For each scenario, we created CAD geometry, FEA geometry, stresses, restrictions, and material.

For the Type I tooth, we conducted the analysis in two cases: with the existing old cutting-tooth holder and the proposed new tooth-holder (which better encompasses the tooth's tail when mounted). For all three types of teeth, it was concluded that:

- in the case of tooth mounting by a holder of the old type, the von Mises tension is maximal in the area of the tooth's tail being located between the holders and the shoulder;

- mounting the cutting-tooth into the old tooth holder causes the von Mises stress to be maximal in the tail area of the tooth at the intersection of the support and the joint;

- mounting the cutting tooth into the proposed new tooth holder makes the von Mises stress maximal at the clearance area corresponding to the setting plane of the tooth;

- regardless of the tooth-holder type used, the maximum deformation appears at the tip of the cutting tooth. It was observed that, in the case of the old tooth holder, the deformations are larger than in the case of the new proposed tooth holder;

- it is shown that increasing the sharpening angle results in decreases in both the deformations and von Misses stresses of the cutting tooth.
The results of this analysis are similar to the past results obtained using analytical methods of research conducted by the Mechanical, Industrial, and Transport Engineering Department [11].

\section{References}

[1] Dimirache G., Zamfir, V.: Ingineria sistemelor mecanice, Editura Focus, Petroşani 2002.

[2] Iliaş N.: Maşini miniere, exemple de calcul, Editura Tehnică Bucureşti 1993.

[3] Kovacs I., Iliaş N., Nan M.S.: Regimul de lucru al combinelor miniere, Editura Universitas, Petroşani 2000.

[4] Ovidiu-Bogdan T., Iosif A., Dumitru P.F.: Comparative study regarding the break-out angle and specific energy consumption at overburden rock and lignite cutting from Oltenia coalfield, "Quality-Access to Success" 2017, 18: 386-389.

[5] Lazăr M., Andraş I., Faur F., Andraş A.: Influence of Physical, Mechanical and Technological Characteristics of Coal and Overburden Rocks on the Excavation Process, SGEM2017 Conference Proceedings 2017, 17, 13: 445-452.

[6] Marian I.: Utilaje de încărcare şi transport minier, Editura Tehnică, Bucureşti 1991.

[7] Nan M.S.: Parametrii procesului de excavare la excavatoarele cu rotor, Editura Universitas, Petroşani 2007.

[8] Akin J.E.: Finite Element Analysis Concepts via SolidWorks, World Scientific, 2009.

[9] Kurowski P.M.: Engineering Analysis with SOLIDWORKS Simulation, SDC Publications, Mission, USA 2015.

[10] Kovacs I., Nan M.S., Andraş I., Jula D.: Stabilirea regimului extrem de funcţionare a excavatoarelor cu roată portcupe, Proceedings “Universitaria ROPET 2002”, 17-19 octombrie 2002, Petroşani.

[11] Studiul comportării la tăiere mecanică a rocilor sterile din descoperta stratelor de lignit şi a lignitului în carierele aparţinând CNL Oltenia în vederea cresterii performanţelor tehnice şi economice a extragerii cu ajutorul excavatoarelor cu rotor, Contract de cercetare ştiinţifică, Catedra de maşini şi instalații, Petroşani 2002.

FLORIN-DUMITRU POPESCU, Prof. Ph.D. SORIN MIHAI RADU, Prof. Ph.D. ANDREI ANDRAS, Lecturer, Ph.D.

Department of Mechanical, Industrial and Transportation Engineering, University of Petrosani 20 Universităţii str., 332006 Petroşani, HD, Romania fpopescu@gmail.com 


\title{
Ulepszenia w zakresie wydajności funkcjonalnej zębów tnących zamocowanych na koparkach wielonaczyniowych w zagłębiu węgla Oltenia w Rumunii
}

\begin{abstract}
Wartości sit wypadkowych, które działaja na zęby tnace koparek wielonaczyniowych, moga być albo wyliczone, albo określone przy użyciu eksperymentalnych metod. Na tej podstawie byly zaprojektowane $i$ wykonane położenie $i$ parametry organów roboczych $w$ trakcie procesu urabiania. Naprężenia i odksztatcenia zębów w trakcie procesu urabiania zależa od ich położenia na czerpaku koparki, które jest określone przez metodę dopasowania zębów. W niniejszym opracowaniu została przedstawiona analiza naprężén i odksztatceń w przypadku obecnie używanego uchwytu zębów, a następnie został zaproponowany nowy typ uchwytów oraz wykonano to samo opracowanie na nowym typie uchwytu, przy użyciu przeznaczonego do tej analizy oprogramowania SolidWorks@.
\end{abstract}

Słowa kluczowe: odkształcenie, naprężenie, wirnik, zęby tnace, koparki wielonaczyniowe, MES, AES

\section{WSTĘP}

$\mathrm{Na}$ zlecenie elektrowni Oltenia przeprowadzono analizę porównawczą sił i odkształceń istniejącego i nowego uchwytu zęba, który został wdrożony w kopalni odkrywkowej Oltenia. Do pracy wykorzystano analizę elementów skończonych (AES). Jest to metoda analizy numerycznej stosowana do rozwiązywania problemów $\mathrm{w}$ różnych dziedzinach inżynierii. W inżynierii mechanicznej jest szeroko stosowana do rozwiązywania problemów strukturalnych, wibracyjnych i termicznych.

\section{WPŁYW LOKALIZACJI ZĘBÓW TNĄCYCH NA ŁYŻKĘ ORAZ NA PARAMETRY GEOMETRYCZNE I WYTRZYMAŁOŚCIOWE}

Ułożenie i orientacja zębów tnących na krawędzi tnącej czerpaka wpływa na ich geometrię i wytrzymałość [1-2]. Wielkość i kierunek wektora prędkości są określone przez wahania prędkości $v_{p}$ (przy czym zakres wahań uzależniony jest od rodzaju mechanizmu obrotowego). Na prędkość obrotu $v_{p}$ składa się prędkość skrawania $v_{t}$, która uważana jest za stałą [3].

Aby przestudiować wpływ ułożenia zębów tnących na czerpakach na parametry geometryczne i wytrzy- małościowe, określa się następujące płaszczyzny, za pomocą których można wyrazić położenie każdego tnącego zęba:

- płaszczyzna ustawiania, określona przez krawędź tnącą zęba i jej czoło ustawiania (rys. 1);

- płaszczyzna zgarniająca, określona przez krawędź tnącą zęba i jej czoło zgarniania (rys. 1);

- płaszczyzna symetrii - prostopadła do krawędzi tnącej zęba i przechodzi przez środek krawędzi tnącej zęba (rys. 1);

- płaszczyzna skrawania, określona przez krawędź tnącą zęba i wektor wypadkowy prędkości (rys. 2);

- płaszczyzna prędkości - prostopadła do płaszczyzny cięcia i zawiera wypadkowy wektor prędkości (rys. 2).

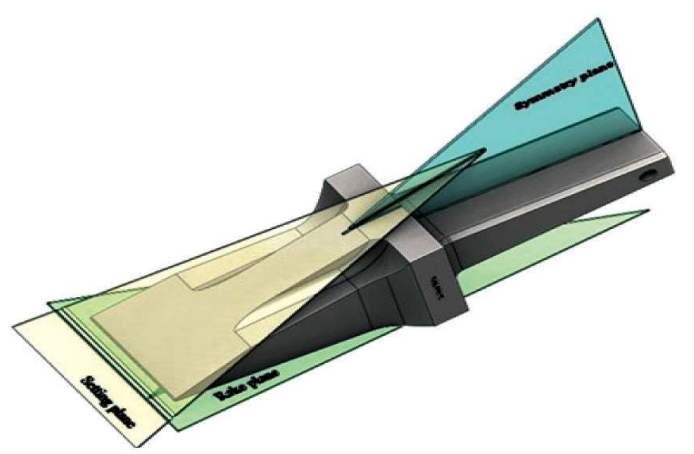

Rys. 1. Ptaszczyzny ustawiania, zgarniania i symetrii 


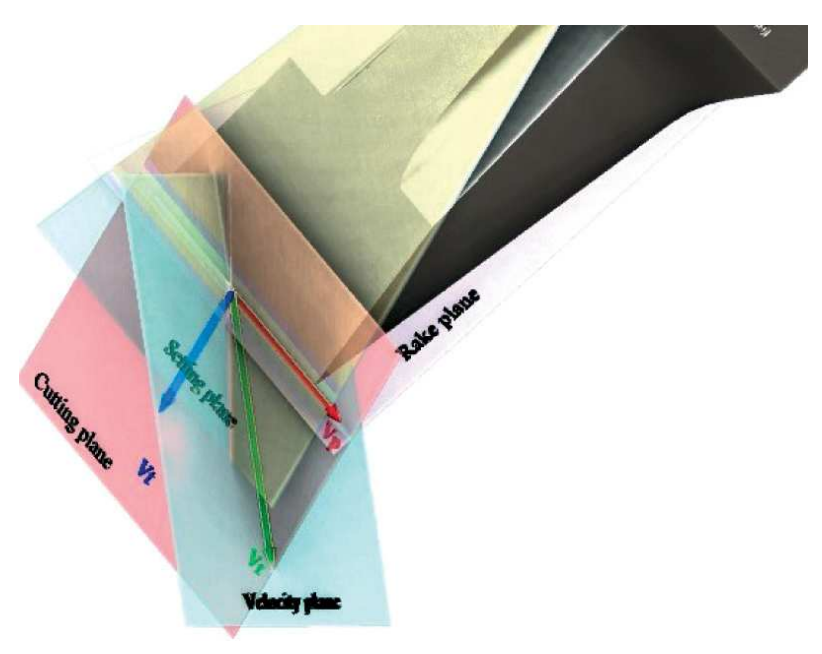

Rys. 2. Prędkości obrotu, skrawania i wypadkowe oraz płaszczyzny skrawania i prędkości

Jeżeli wypadkowy wektor prędkości jest prostopadły do krawędzi tnącej zęba, wówczas płaszczyzna prędkości i płaszczyzna symetrii nakładają się na siebie.

$\mathrm{Na}$ rysunku 2 kąt ustawienia mierzony jest pomiędzy płaszczyzną ustawienia a płaszczyzną skrawania, a kąt zaostrzenia mierzony jest pomiędzy płaszczyzną skrawania a płaszczyzną zgarniania. Tutaj odnotowaliśmy prędkość obrotu $v_{t}$, prędkość skrawania i prędkość wypadkową $v_{r}$.

Kąt pomiędzy linią wynikającą z przecięcia płaszczyzny skrawania z płaszczyzną symetrii i wypadkowym wektorem prędkości oznacza kąt ułożenia zęba na krawędzi tnącej czerpaka. Umieszczenie zęba na krawędzi skrawania wykonuje się za pomocą jego uchwytu [4].

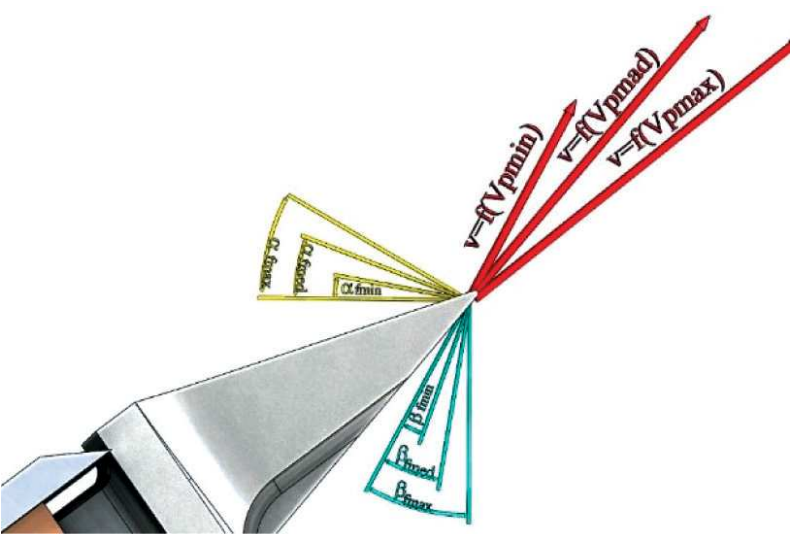

Rys. 3. Charakterystyczne katy podczas urabiania

Podczas urabiania działają następujące charakterystyczne kąty (rys. 3):

- kąt ustawienia $\beta_{f}$ pomiędzy kierunkiem prędkości wypadkowej a linią przecięcia pomiędzy płaszczyzną ustawiania a płaszczyzną prędkości;
- kąt skrawania pomiędzy prędkością wypadkową, kierunkiem a linią przecięcia między płaszczyzną zgarniania a płaszczyzną prędkości;

- kąt zaostrzenia pomiędzy linią przecięcia płaszczyzn ustawienia a płaszczyzną prędkości, odpowiednio linią przecięcia pomiędzy płaszczyzną odstępu a płaszczyzną prędkości;

- kąt zgarniania jest komplementarny w stosunku do kąta ustawienia $\beta_{f}$.

\section{OKREŚLANIE NAPRĘŻEŃ I ODKSZTAKCEŃ DLA PRZECINAKOWYCH ZĘBÓW TNĄCYCH PRZY UŻYCIU STAREGO UCHWYTU ZĘBÓW}

W wyniku badań przeprowadzonych na Uniwersytecie Petroszany dotyczących elektrowni Oltenia, zaproponowano trzy typy zębów dla koparki wielonaczyniowej. Rysunek 4 przedstawia konstrukcję takiego zęba, a rysunek 5 pokazuje różnice wymiarowe pomiędzy trzema typami zębów [5, 6].

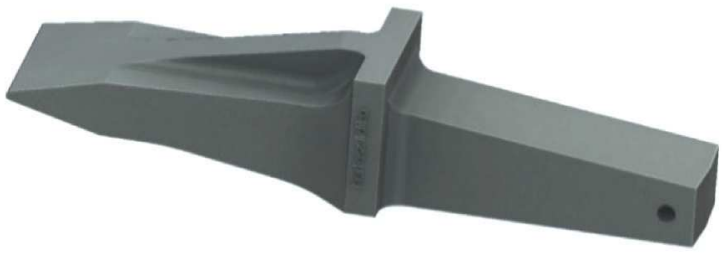

Rys. 4. Ząb tnacy wybrany do analizy

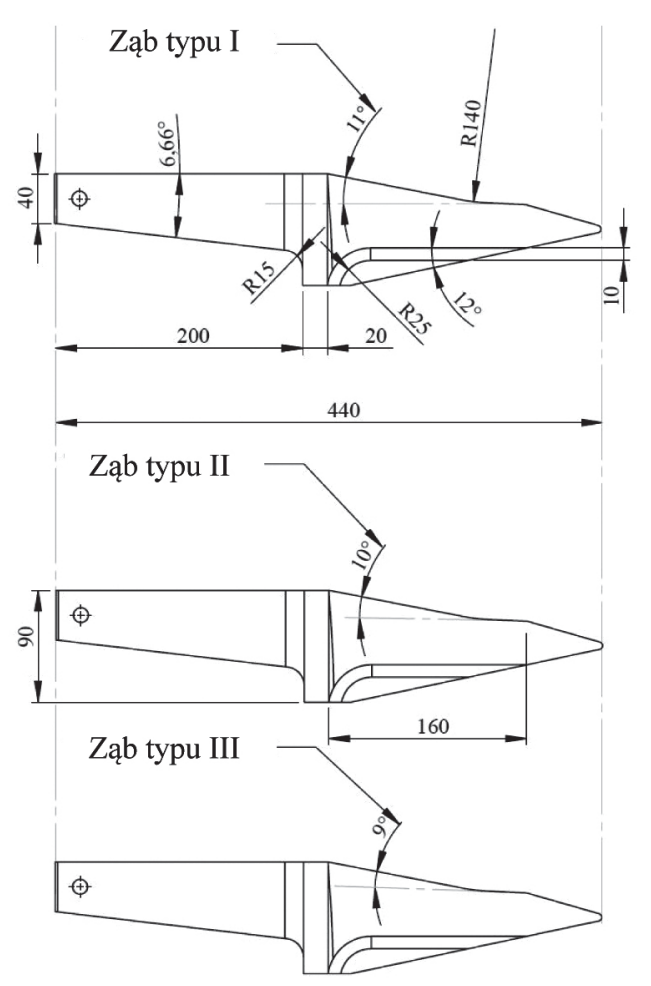

Rys. 5. Wymiary proponowanego typu zęba tnacego 
Wymiary odpowiadają trzem różnym kategoriom wydobywanego materiału, z których każdy ma inny opór skrawania:

- skały nadkładowe, które łatwo ulegaja przesunięciu, charakteryzują się niską wartością właściwego oporu skrawania $A=200-450 \mathrm{~N} / \mathrm{cm}$,

- skały nadkładowe i węgiel brunatny o średnim właściwym oporze skrawania $A=450-800 \mathrm{~N} / \mathrm{cm}$,

- węgiel brunatny o wyższym właściwym oporze skrawania $A=800-1200 \mathrm{~N} / \mathrm{cm}$.

Naprężenia na zębie tnącym to: $F_{x}=60 \mathrm{kN}$; $F_{y}=18 \mathrm{kN} ; F_{z}=10 \mathrm{kN}$. W stosunku do powierzchni zęba będziemy mieć następujące siły składowe [7]:

$$
\begin{aligned}
& F_{y 1}=F_{x} \cos \alpha-F_{y} \cos \gamma=25.857 \cdot 10^{3} \mathrm{~N} \\
& F_{x 1}=F_{x} \sin \alpha-F_{y} \sin \gamma=36.198 \cdot 10^{3} \mathrm{~N} \\
& F_{z 1}=10 \cdot 10^{3} \mathrm{~N}
\end{aligned}
$$

Rysunek 6 przedstawia odkształcenie, a rysunek 7 naprężenie von Misesa wynikające $z$ analizy elementów skończonych (AES) na typie 1, kiedy ząb zamocowany jest za pomocą starego uchwytu zęba.

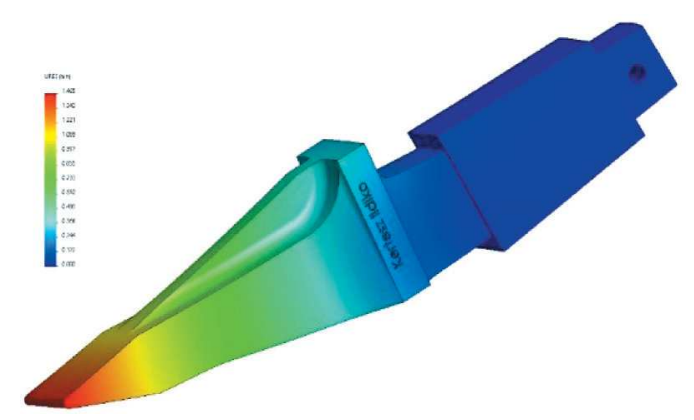

Rys. 6. Odksztatcenie na zębie tnacym typu I w przypadku jego mocowania za pomoca starego uchwytu zęba

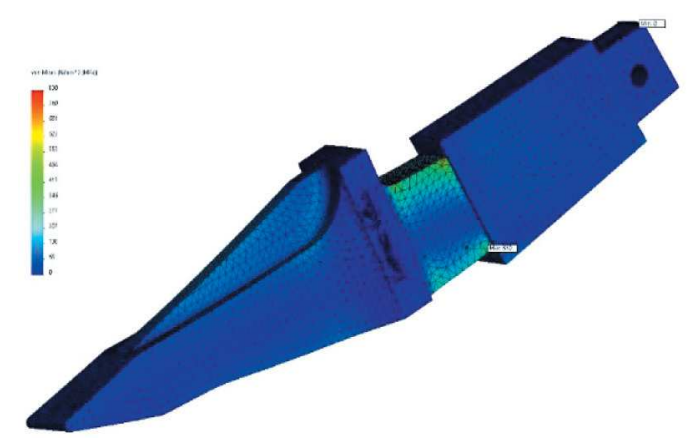

Rys. 7. Naprężenie von Misesa na zębie tnacym typu I kiedy jest on mocowany za pomoca starego uchwytu zęba
Można zaobserwować, że maksymalne odkształcenie występuje w obszarze ostrza zęba, a najbardziej naprężone punkty struktury zęba znajdują się w jego części chwytowej, pomiędzy podporą zęba a jego podstawą.

\section{PROPONOWANE ROZWIAZANIE MAJACE NA CELU ZMNIEJSZENIE NAPRĘŻEŃ DZIALAJACYCH NA ZAB TNACY}

Jak pokazano w poprzednim rozdziale, punkty maksymalnego naprężenia są umiejscowione tam, gdzie część zespołu ząb-uchwyt tworzy całość. W omawianym przypadku jest to obszar przejścia z części uchwytu zęba na część roboczą zęba. Następnie proponujemy i analizujemy typ uchwytu zęba, który będzie lepiej obejmował jego część chwytową. Rysunki 8 i 9 przestawiają szczegóły nowej wersji uchwytu zęba.

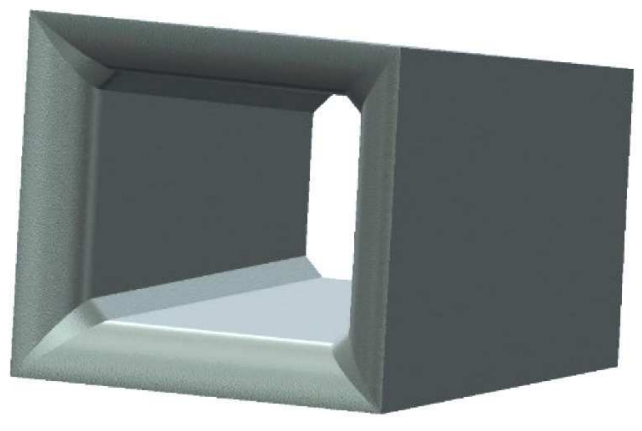

Rys. 8. Proponowany uchwyt do mocowania zęba tnącego czerpaka
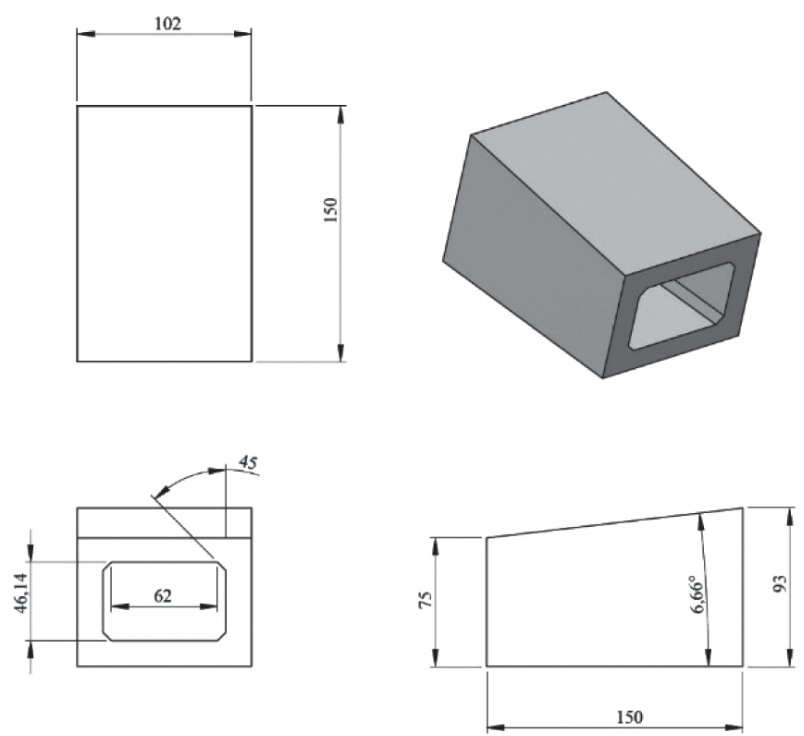

Rys. 9. Wymiary i geometria proponowanej nowej podpory zęba 


\section{OKREŚLANIE NAPRĘŻEŃ I ODKSZTAŁCEŃ ZĘBA TNACEEGO \\ PRZY WYKORZYSTANIU \\ NOWEGO UCHWYTU ZĘBA}

Narzucając naprężenia z rozdziału 2, określono odkształcenia i naprężenia wymiarów trzech typów zęba, proponowanych do analizy w przypadku, gdy

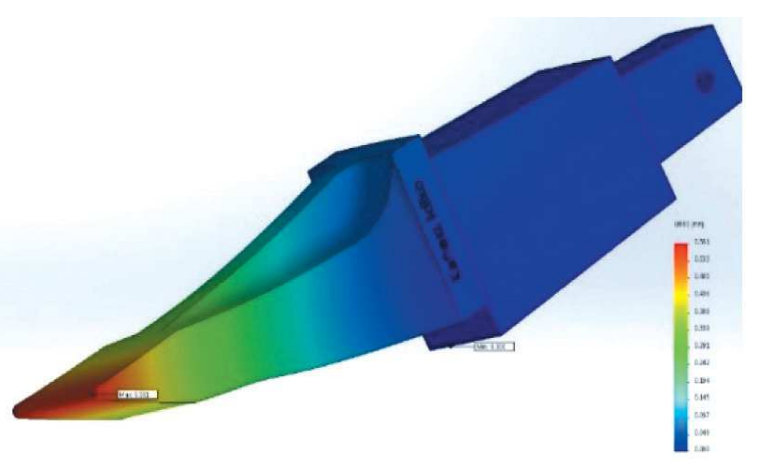

Rys. 10. Odksztatcenie zęba typu I w przypadku jego zamocowania za pomoca proponowanego nowego uchwytu zęba

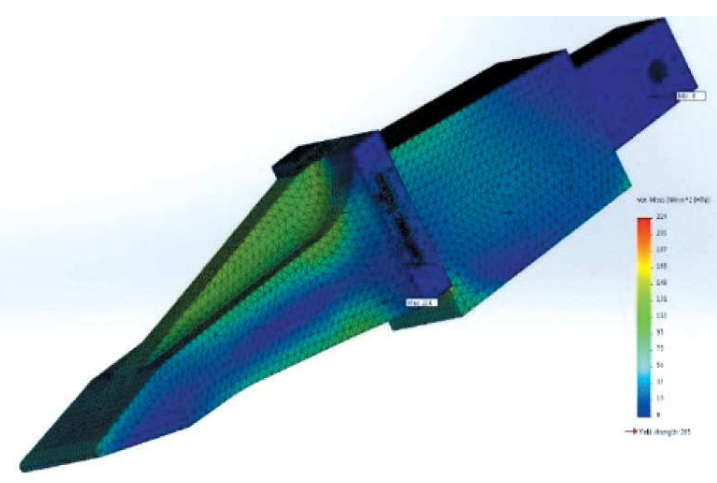

Rys. 11. Naprężenie von Misesa zęba typu I w przypadku jego zamocowania za pomoca proponowanego nowego uchwytu zęba

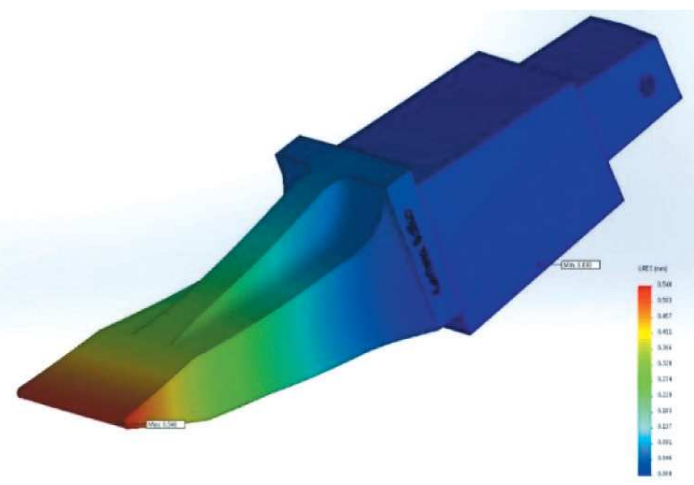

Rys. 12. Odkształcenie zęba typu II w przypadku jego zamocowania za pomoca proponowanego nowego uchwytu zęba jest on mocowany na czerpaku z nowym uchwytem zęba proponowanym w akapicie $3[8,9]$.

Rysunki 10, 12 i 14 przedstawiają odkształcenia, a rysunki 11, 13 i 15 obrazują odpowiadające trzem typom naprężenia von Misesa. Wyniki uzyskane z wykorzystaniem analizy elementów skończonych dla wymiarów tych rodzajów zębów przedstawiono w tabeli 1.

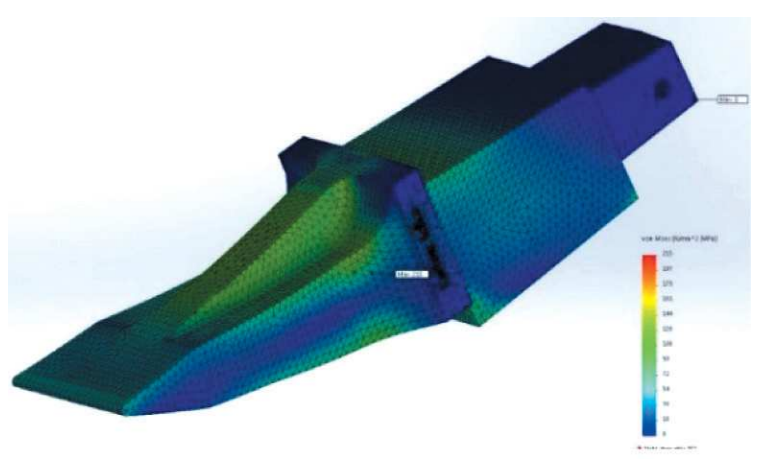

Rys. 13. Naprężenie von Misesa zęba typu II w przypadku jego zamocowania za pomoca proponowanego nowego uchwytu zęba

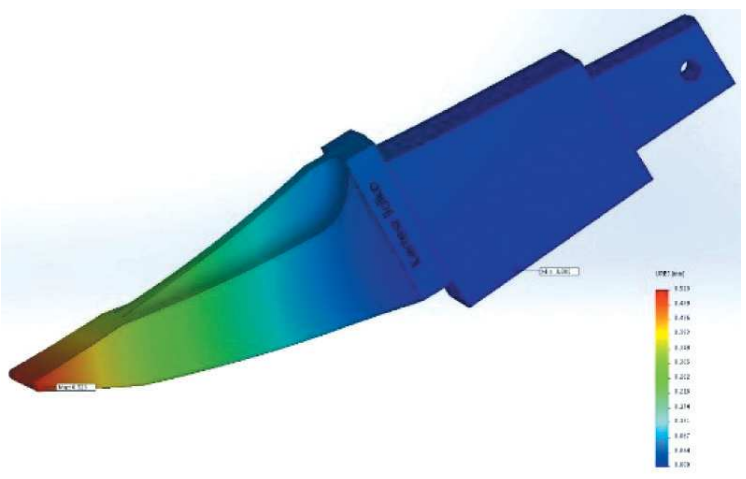

Rys. 14. Odkształcenie zęba typu III w przypadku jego zamocowania za pomoca proponowanego nowego uchwytu zęba

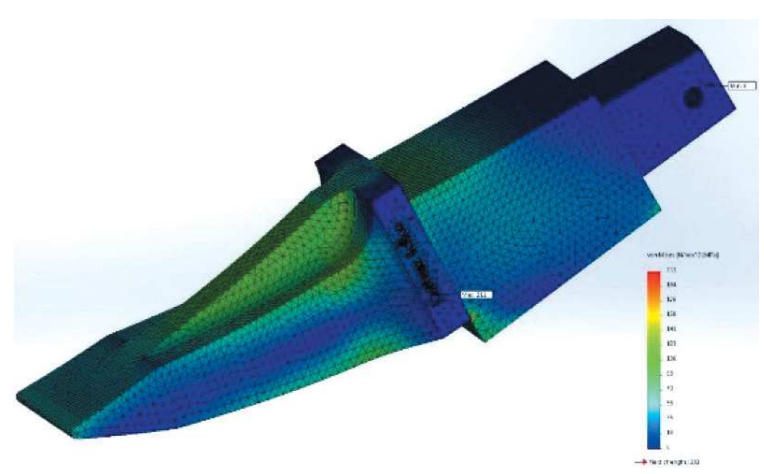

Rys. 15. Naprężenie von Misesa zęba typu III w przypadku jego mocowania za pomoca proponowanego nowego uchwytu zęba 
Tabela 1

Zestawienie wyników uzyskanych dla trzech typów zębów po analizie elementów skończonych

\begin{tabular}{|c|c|c|c|c|c|}
\hline \multirow{2}{*}{$\mathbf{N r}$} & \multirow{2}{*}{ Typ zęba } & \multirow{2}{*}{ Typ uchwytu } & Kąt & Odksztalcenie & Naprężenie \\
\cline { 5 - 6 } & & & {$\left[{ }^{\circ}\right]$} & {$[\mathbf{M m}]$} & {$\left[\mathbf{N} / \mathbf{m m}^{\mathbf{2}}\right]$} \\
\hline 1 & \multirow{2}{*}{ I } & stary & 11 & 1,465 & 829 \\
\cline { 5 - 6 } & & nowy & & 0,581 & 224 \\
\hline 3 & II & nowy & 10 & 0,548 & 215 \\
\hline 4 & III & nowy & 9 & 0,523 & 211 \\
\hline
\end{tabular}

\section{WNIOSKI}

Symulacja zachowania zębów tnących w przypadku ich zamontowania na koparkach wielonaczyniowych przy użyciu analizy elementów skończonych została oparta na wynikach uzyskanych w ciaggu wielu lat na Wydziale Inżynierii Mechanicznej, Przemysłowej i Transportowej w trakcie projektów badawczych mających na celu polepszenie wydajności koparek wielonaczyniowych używanych w Zagłębiu Węglowym Oltenia.

Badania dotyczyły trzech typów zębów o różnych wymiarach i zostały przeprowadzone przy użyciu analizy elementów skończonych. We wszystkich przypadkach użyto zespołu zęba i podpory zęba. Dla każdego scenariusza opracowano model CAD, przeprowadzono analizy elementów skończonych, wyznaczono naprężenia, określono ograniczenia i ustalono rodzaj materiału.

Dla zęba typu I przeprowadzono analizę w dwóch przypadkach: $\mathrm{z}$ istniejącym, starym uchwytem zęba tnącego oraz z zaproponowanym nowym uchwytem zęba, który lepiej obejmuje jego część chwytową po zamocowaniu. W odniesieniu do wszystkich trzech typów zębów stwierdzono, że:

- w przypadku mocowania zęba za pomocą uchwytu starego typu naprężenie von Misesa jest maksymalne w obszarze części chwytowej zęba, która znajduje się pomiędzy uchwytem a podstawą;

- mocowanie zęba tnącego w starym uchwycie powoduje, że naprężenie von Misesa jest maksymalne w obszarze części chwytowej zęba, w punkcie przecięcia podpory i łączenia;

- mocowanie zęba tnącego w zaproponowanym nowym uchwycie sprawia, że naprężenie von Misesa jest maksymalne w obszarze prześwitu odpowiadającym płaszczyźnie ustawienia zęba;

- niezależnie od użytego typu uchwytu zęba maksymalne odkształcenie pojawia się na ostrzu zęba tnącego - zaobserwowano, że w przypadku starego uchwytu zęba odkształcenia są większe niż w przypadku zaproponowanego nowego uchwytu;
- wykazano, że w wyniku zwiększenia kąta zaostrzenia zmniejszają się zarówno odkształcenia, jak i naprężenia von Misesa zęba tnącego.

Wyniki tej analizy są zbliżone do wyników badań przeprowadzonych w przeszłości na Wydziale Inżynierii Mechanicznej, Przemysłowej i Transportowej, przy użyciu metod analitycznych.

\section{Literatura}

[1] Dimirache G., Zamfir V.: Ingineria sistemelor mecanice, Editura Focus, Petroşani 2002.

[2] Iliaş N.: Maşini miniere, exemple de calcul, Editura Tehnică Bucureşti 1993.

[3] Kovacs I., Iliaş N., Nan M.S.: Regimul de lucru al combinelor miniere, Editura Universitas, Petroşani 2000.

[4] Ovidiu-Bogdan T., Iosif A., Dumitru P.F.: Comparative study regarding the break-out angle and specific energy consumption at overburden rock and lignite cutting from Oltenia coalfield, „Quality-Access to Success” 2017, 18: 386-389.

[5] Lazăr M., Andraș I., Faur F., Andras A.: Influence of Physical, Mechanical and Technological Characteristics of Coal and Overburden Rocks on the Excavation Process, SGEM2017 Conference Proceedings 2017, 17, 13: 445-452.

[6] Marian I.: Utilaje de încărcare şi transport minier, Editura Tehnică, Bucureşti 1991.

[7] Nan M.S.: Parametrii procesului de excavare la excavatoarele cu rotor, Editura Universitas, Petroşani 2007.

[8] Akin J.E.: Finite Element Analysis Concepts via SolidWorks, World Scientific, 2009.

[9] Kurowski P.M.: Engineering Analysis with SOLIDWORKS Simulation, SDC Publications, Mission, USA 2015.

[10] Kovacs I., Nan M.S., Andraş I., Jula D.: Stabilirea regimului extrem de functionare a excavatoarelor cu roată portcupe, Proceedings ,Universitaria ROPET 2002”, 17-19 Octombrie 2002, Petroşani.

[11] Studiul comportării la tăiere mecanică a rocilor sterile din descoperta stratelor de lignit şi a lignitului în carierele aparţinând CNL Oltenia în vederea creşterii performanţelor tehnice şi economice a extragerii cu ajutorul excavatoarelor cu rotor, Contract de cercetare ştiinţifică, Catedra de maşini şi instalaţii, Petroşani 2002.

prof. FLORIN-DUMITRU POPESCU prof. SORIN MIHAI RADU

dr inż. ANDREI ANDRAŞ

Department of Mechanical, Industrial and Transportation Engineering,

University of Petroşani

20 Universităţii str., 332006 Petroşani, HD,

Romania

fpopescu@gmail.com 